\title{
Hubungan Pengetahuan Remaja Putri tentang Personal Hygiene dengan Kejadian Keputihan
}

\author{
Yefan Adji $1^{*}$, Siti Hadija Batjo ${ }^{2}$, Hastuti Usman² \\ ${ }^{1}$ RS Pratama Abd Chalik Masulili Pagimana \\ 2Jurusan Kebidanan, Poltekkes Kemenkes Palu \\ *Email korespondensi: yefan@yahoo.com
}

Article Info

ABSTRACT

Article history:

Submitted: 2019-08-13

Accepted: $2019-12-28$

Published: 2019-12-30

Keywords:

Knowledge, Pesonal Hygiene, Leucorrhoea
Leucorrhoea is a clinical disorder that is often complained of by all women. For young women who are just entering puberty with all forms of phenomenal changes in themselves, this problem will have a negative impact in the future if it is not addressed early. The purpose of this study was to determine the relationship of adolescent girls' knowledge about personal hygiene with Leucorrhoea. This research was an analytic research with a cross-sectional approach. The population of this study was 36 female students in class $X$ and class XI in Pagimana I Senior High School. The sampling technique used purposive random sampling. The results were obtained by 33 knowledgeable (91.7\%). Adolescents who have good knowledge and experience Leucorrhoea as many as 19 people (57.6), who do not Leucorrhoea 14 people (42.4\%), who lack knowledge and experience Leucorrhoea as much as two people $(66.7 \%)$, who do not have Leucorrhoea as much as one person (33.3\%). Chi-square test showed $p$-value $=1,000$. The conclusion of the study, there is no relationship between the knowledge of adolescent girls about personal hygiene with Leucorrhoea. Suggestions for adolescent girls to maintain good personal hygiene to prevent Leucorrhoea.

\section{ABSTRACT}

Kata kunci:

Pengetahuan; Kebersihan Diri; Keputihan
Keputihan merupakan salah satu gangguan klinis yang sering dikeluhkan oleh semua wanita. Bagi remaja putri yang baru memasuki masa pubertas dengan segala bentuk fenomene perubahan pada diri mereka, bila masalah ini tidak ditangani sejak dini akan berdampak negatif dikemudian hari. Tujuan penelitian ini untuk mengetahui hubungan pengetahuan remaja putri tentang personal hygiene dengan kejadian keputihan. Penelitian ini merupakan jenis penelitian analitik dengan pendekatan cross sectional. Populasi penelitian ini adalah remaja putri kelas $X$ dan kelas XI di SMA Negeri I Pagimana sebanyak 36 responden. Teknik pengambilan sampel menggunakan purposive rondom sampling, Hasil penelitian diperoleh remaja putri berpengetahuan baik sebanyak 33 orang (91,7\%). Remaja yang berpengetahuan baik dan mengalami keputihan sebanyak 19 orang $(57,6)$, yang tidak keputihan 14 orang $(42,4 \%)$, yang berpengetahuan kurang dan mengalami keputihan sebayak 2 orang $(66,7 \%)$, yang tidak keputihan sebanyak 1 orang (33,3\%). Uji Chi-square diperoleh nilai $p=1,000$. Kesimpulan penelitian, tidak ada hubungan pengetahuan remaja putri tentang personal hygiene dengan kejadian keputihan. Saran untuk remaja putri agar menjaga personal hygiene yang baik untuk mencegah keputihan. 


\section{PENDAHULUAN}

Masa remaja merupakan suatu periode masa pematangan organ reproduksi manusia dan sering disebut masa pubertas, dan ditandai oleh berbagai perubahan. Perubahan alamiah dalam diri remaja sering berdampak pada permasalahan yang cukup serius. ${ }^{1}$ Perubahan hormonal pada remaja akan menyebabkan masalah keputihan yaitu keluarnya cairan dari alat genital yang tidak berupa darah. Dalam kondisi normal, sekret vagina tersebut tampak jernih, putih keruh atau berwarna kekuningan ketika mengering pada pakaian. Sekret ini non-irritan, tidak menganggu, tidak terdapat darah. ${ }^{2}$

Di Indonesia sebanyak $75 \%$ wanita pernah mengalami keputihan minimal satu kali dalam hidupnya dan $45 \%$ diantaranya bisa mengalami keputihan sebanyak dua kali atau lebih. ${ }^{3}$ Kurangnya pengetahuan wanita di Indonesia tentang keputihan sehingga mereka menganggap keputihan sebagai hal yang umum dan sepele, karena merasa malu jika mengalami keputihan, sehingga enggan berkonsultasi ke tenaga kesehatan. ${ }^{4,5}$ Padahal keputihan tidak dapat dianggap sepele. Perempuan yang mengalami keputihan akibat infeksi berulang atau menahun dapat mengalami gangguan pada organ reproduksi dan dapat juga merupakan tanda dari adanya tumor serta merupakan gejala dari kanker leher rahim yang bisa berujung pada kematian. ${ }^{6}$

Salah satu faktor penyebab terjadinya keputihan adalah personal hygiene alat genetalia. Remaja putri diharapkan lebih mengerti pentingnya personal hygiene (perawatan genetalia) sehingga tidak berpengaruh terhadap kesehatan reproduksi jangka pendek maupun jangka panjang. Penelitian Prasetyowati (2013) menunjukan bahwa remaja yang membersihkan daerah kewanitaannya kurang baik mempunyai peluang 3,5 kali terjadi keputihan dibandingkan pada remaja puteri yang membersihkan daerah kewanitaan dengan baik. ${ }^{5}$

Berdasarkan hasil studi pendahuluan yang dilaksanakan pada tanggal 1 Desember 2018 di SMA Negeri 1 Pagimana diperoleh informasi dari 10 siswi yang mengalami keputihan. Hal inilah yang mendorong penulis untuk melakukan penelitian mengenai hubungan pengetahuan remaja putri tentang personal hygiene dengan kejadian keputihan di SMA Negeri I Pagimana, karena remaja putri harus di berikan perhatian yang lebih dalam hal kesehatan reproduksinya mengingat perempuan merupakan seseorang yang akan melahirkan generasi penerus bangsa. Tujuan penelitian ini adalah untuk mengetahui hubungan pengetahuan remaja putri tentang personal hygiene dengan kejadian keputihan di SMA Negeri I Pagimana.

\section{METODE PENELITIAN}

Penelitian ini menggunakan metode analitik dengan jenis penelitian crosssectional dimana variabel - variabel yang termasuk faktor resiko dan variabel variabel yang temasuk efek diobservasi sekaligus pada waktu yang bersamaan. Penelitian dilakukan pada siswi SMA Negeri I Pagimana pada bulan Januari sampai Juni 2019. Cara pengambilan sampel yang digunakan dalam penelitian ini adalah purposive random sampling. Penentuan besar sampel menggunakan rumus Slovin, jumlah sampel adalah 36 orang terdiri dari remaja putri kelas $\mathrm{X}$ dan kelas XI. Pengambilan sampel dilakukan secara acak menggunakan tehnik purposive random sampling, berdasarkan kriteria inklusi yaitu remaja putri kelas X dan XI, usia 14 tahun sampai 17 tahun dan bersedia menjadi responden. Variabel independen dalam penelitian ini adalah pengetahuan personal hygiene dan variabel dependen adalah kejadian keputihan. Pengumpulan data melalui data primer dan data sekunder. Analisis menggunakan uji Chi Square. 


\section{HASIL PENELITIAN}

Berdasarkan hasil penelitian diperoleh hasil sebagai berikut:

Tabel 1. Distribusi Frekuensi Remaja Putri berdasarkan Pengetahuan tentang Personal Hygiene dan Kejadian Keputihan di SMA Negeri I Pagimana.

\begin{tabular}{lcc}
\hline Variabel & Frekuensi $(\mathbf{n = 3 6 )}$ & Persentase (\%) \\
\hline Umur & & \\
14 & 7 & 19,4 \\
15 & 16 & 44,4 \\
16 & 10 & 27,8 \\
17 & 3 & 8,3 \\
Kelas & & \\
X & 20 & 55,6 \\
XI & 16 & 44,4 \\
Pengetahuan & & \\
Baik & 33 & 91,7 \\
$\quad$ Kurang & 3 & 8,3 \\
Kejadian Keputihan & & \\
$\quad$ Keputihan & 21 & 58,3 \\
$\quad$ Tidak Keputihan & 15 & 41,7 \\
\hline
\end{tabular}

Tabel 1 menunjukkan gambaran distribusi frekuensi remaja putri berdasarkan pengetahuan tentang personal hygiene di SMA Negeri I Pagimana dimana sebagaian besar adalah berpengetahuan baik yaitu $91,7 \%$ dan yang berpengetahuan kurang adalah 8,3\%. Tabel 1 menunjukkan gambaran distribusi frekuensi kejadian keputihan pada remaja putri di SMA Negeri I Pagimana, dimana remaja puteri yang mengalami keputihan sebanyak $58,3 \%$ dan yang tidak megalami keputihan adalah $41,7 \%$.

Tabel 2. Hubungan Pengetahuan Remaja Putri tentang Personal Hygiene dengan Kejadian Keputihan di SMA Negeri I Pagimana

\begin{tabular}{|c|c|c|c|c|c|c|c|}
\hline \multirow{3}{*}{ Pengetahuan } & \multicolumn{6}{|c|}{ Keputihan } & \multirow[t]{3}{*}{ p-value } \\
\hline & \multicolumn{2}{|c|}{ Ya } & \multicolumn{2}{|c|}{ Tidak } & \multicolumn{2}{|c|}{ Total } & \\
\hline & $f$ & $\%$ & $\mathbf{f}$ & $\%$ & $f$ & $\%$ & \\
\hline $\begin{array}{c}\text { Kurang } \\
\text { Baik }\end{array}$ & $\begin{array}{r}2 \\
19\end{array}$ & $\begin{array}{l}66,7 \\
57,6\end{array}$ & $\begin{array}{r}1 \\
14\end{array}$ & $\begin{array}{l}33,3 \\
42,4\end{array}$ & $\begin{array}{r}3 \\
33\end{array}$ & $\begin{array}{l}100 \\
100\end{array}$ & 1,000 \\
\hline Total & 21 & 58,3 & 15 & 41,7 & 36 & 100 & \\
\hline
\end{tabular}

Tabel 2 menunjukkan hubungan pengetahuan remaja putri tentang personal hygiene dengan kejadian keputihan di SMA Negeri I Pagimana, dimana remaja putri dengan kategori pengetahuan kurang yang tidak keputihan berjumlah 1 orang $(33,3 \%)$, yang keputihan berjumlah 2 orang $(66,7 \%)$, sedangkan remaja putri dengan kategori pengetahuan baik yang tidak keputihan 14 orang $(42,4 \%)$, yang keputihan berjumlah 19 orang $(57,6 \%)$. Hasil uji Chi Square diperoleh nilai $p 1,000>\alpha(0,05)$ sehingga dapat disimpulkan bahwa tidak ada hubungan yang signifikan antara pengetahuan remaja putri tentang personal hygiene dengan kejadian keputihan di SMA Negeri I Pagimana. 


\section{PEMBAHASAN}

Berdasarkan hasil data tabel 1 menunjukkan bahwa sebagian besar pengetahuan remaja tentang personal hygiene dalam kategori baik yaitu sebanyak 33 orang dan kategori berpengetahuan kurang sebanyak 3 orang. Menurut asumsi peneliti, responden dengan kategori pengetahuan baik disebabkan karena responden sudah pernah mendapatkan informasi atau penyuluhan tentang personal hygiene dari petugas kesehatan. Hal ini didukung dengan hasil wawancara dengan salah seorang guru di SMA Negeri 1 Pagimana, pada saat pengambilan data awal yang menyatakan bahwa di SMA Negeri 1 Pagimana sudah pernah dilakukan penyuluhan tentang personal hygiene oleh petugas Puskesmas Pagimana.

Pengetahuan sangat erat hubungannya dengan pendidikan, dimana diharapkan dengan pendidikan yang tinggi maka orang tersebut akan semakin luas pula pengetahuannya. Akan tetapi perlu ditekankan, bukan berarti seseorang yang berpendidikan rendah mutlak berpengetahuan rendah pula. ${ }^{7} \mathrm{Hal}$ ini mengingat bahwa peningkatan pengetahuan tidak mutlak diperoleh melalui pendidikan non formal. Sesuai dengan penelitian yang dilakukan oleh Ramayanti bahwa kebersihan seseorang adalah suatu tindakan untuk memelihara kebersihan dan kesehatan seseorang untuk kesejahteraan fisik dan psikis, apabila ingin terhindar dari keputihan, maka harus menjaga kebersihan daerah sensitif itu. ${ }^{8}$ Penelitian ini sejalan dengan penelitian yang dilakukan oleh Nurlaila dan Mardiana di SMP Surya Darma Bandar Lampung, yang menyatakan bahwa pengetahuan itu sendiri dipengaruhi oleh faktor pendidikan formal. $^{9}$

Berdasarkan tabel 2 dimana hasil penelitian dari 36 responden, diperoleh informasi pengetahuan remaja putri tentang personal hygiene dengan ketegori baik tapi mengalami keputihan sebanyak 19 responden dan tidak keputihan 14 responden. Menurut peneliti tidak adanya hubungan antara pengetahuan personal hygiene dengan kejadian keputihan di mana kejadian keputihan banyak terjadi pada remaja putri yang berpengetahuan baik, dengan teori yang digunakan bahwa pengetahuan merupakan dominan yang sangat penting dalam membentuk tindakan seseorang baik dalam merawat diri sendiri dan personal hygiene. Remaja Putri yang berpengetahuan baik tapi tidak paham untuk melakukan pemeliharaan kesehatan diri sendiri, dan pada kenyataannya pengetahuan yang baik banyak mengalami keputihan, hal ini responden kurang paham cara perawatan alat reproduksinya sendiri, dan membaca dimedia masa maupun media elektronik.

Pengetahuan responden berada pada tingkatan tahu tetapi tidak paham dalam melakukan perawatan personal hygiene (alat reproduksi) diri sendiri. Penatalaksanaan keputihan tidak terlepas dari pengetahuan responden, dengan perilaku kebersihan. Pengetahuan remaja tentang keputihan akan mempengaruhi sikap dan perilaku hidup bersih dan sehat.

Pengetahuan merupakan hasil tahu yang terjadi setelah orang mengadakan penginderaan terhadap suatu objek tertentu. Penginderaan terhadap objek terjadi melalui panca indera seperti penglihatan, penciuman, pendengaran, perasa dan peraba dengan sendiri. Menurut Ariani dalam Kamus Besar Bahasa Indonesia, pengetahuan yaitu suatu hal yang dapat diketahui serta berkaitan dengan proses belajar mengajar. ${ }^{10}$ Kegiatan belajar dipengaruhi banyak yang berasal dari faktor dalam, seperti motivasi dan faktor luar berupa sarana informasi yang tersedia, serta keadaan sosial budaya. ${ }^{11}$

Menurut Andira faktor yang dapat berpengaruh terhadap personal hygiene yaitu body image, gambaran individu terhadap dirinya sendiri sangat mempengaruhi 
kebersihan diri misalnya karena adanya perubahan fisik sehingga individu tidak peduli terhadap kebersihan dirinya. ${ }^{12}$ Dari hasil penelitian ini dapat diketahui bahwa pada usia remaja pertengahan pematangan fungsi hormonal wanita akan mengalami ovulasi dan menstruasi, organ reproduksi sangat sensitif, sehingga apabila personal hygiene organ reproduksi tidak terjaga, maka akan menyebabkan keputihan yang memberi dampak negatif pada kesehatan organ reproduksi. Sejalan dengan penelitian yang dilakukan oleh Tulus et al, yang menyatakan bahwa tidak ada hubungan pengetahuan dengan terjadinya keputihan remaja putri di SMA Kristen I Tomohon. ${ }^{13}$ Penelitian ini, tidak sejalan dengan penelitian yang dilakukan oleh Irmayanti dan penelitian yang dilakukukan oleh IImiawati dan Kuntoro yang menyatakan ada hubungan pengetahuan remaja putri tentang personal hygiene dengan kejadian keputihan. ${ }^{14,15}$

Keterbatasan penelitian ini adalah variabel yang diteliti hanya 1 variabel independen saja, padahal masih banyak faktor lain yang berhubungan dengan kejadian keputihan pada remaja putri. Hal ini menurut hasil wawancara dengan salah seorang guru bahwa sudah pernah dilakukan penyuluhan tentang personal hygiene oleh petugas Puskesmas Pagimana.

\section{SIMPULAN DAN SARAN}

Berdasarkan hasil penelitian yang dilakukan dapat diambil kesimpulan bahwa tidak ada hubungan pengetahuan remaja putri tentang personal hygiene dengan kejadian keputihan di SMA Negeri I Pagimana. Diharapkan bagi remaja putri untuk tetap menjaga personal hygiene yang baik serta mengkonsumsi makanan yang sehat untuk mencegah keputihan.

\section{UCAPAN TERIMA KASIH}

Peneliti mengucapkan terima kasih kepada Kepala SMA Negeri I Pagimana yang telah memberikan izin penelitian serta seluruh siswi yang telah bersedia menjadi responden sehingga penelitian ini bisa diselesaikan dengan baik.

\section{DAFTAR PUSTAKA}

1. Maharani. Faktor Risiko Kejadian Kandidiasis Vaginalis pada Akseptor KB. [Surabaya]: Universitas Airlangga; 2009.

2. Wiknjosastro $H$. Radang dan beberapa penyakit lain pada alat genital wanita ilmu kandungan. 2nd ed. Jakarta: Yayasan Bina Pustaka,sarwono Prawirodihardjo; 2002.

3. Badan Kependudukan dan Keluarga Berencana Nasional. Profil Hasil Pendataan Keluarga Tahun 2011. Jakarta: Badan Kependudukan dan Keluarga Berencana Nasional Direktorat Pelaporan dan Statistik; 2012.

4. Dhuangga WP, Misrawati. Efektifitas Pendidikan Kesehatan tentang Hygiene Kewanitaan terhadap Pengetahuan dan Sikap Remaja Putri dalam Menangani Keputihan. J Ners Indones [Internet]. 2012;2(2):116-23. Available from: https://jni.ejournal.unri.ac.id/index.php/JNI/article/view/2021

5. Abrori A, Hernawan AD, Ermulyadi E. Faktor yang Berhubungan dengan Kejadian Keputihan Patologis Siswi SMAN 1 Simpang Hilir Kabupaten Kayong Utara. Unnes J Public Health [Internet]. 2017 Jan 31 [cited 2019 Dec 28];6(1):24. Available from: https://journal.unnes.ac.id/sju/index.php/ujph/article/view/14107

6. Shadine M. Penyakit Wanita: Pencegahan Deteksi Dini dan Pengobatan. Yogyakarta: Citra Pustaka; 2012.

7. Notoatmodjo S. Promosi Kesehatan dan IImu Perilaku. Jakarta: Rineka Cipta; 2007. 
8. Ramayanti. Pola Mikroorganisme Flour Albus Patologis yang Disebabkan oleh Infeksi pada Penderita Rawat Jalan di Klinik. [Semarang]: Fakultas Kedokteran Universias Diponegoro;

9. Nurlaila, Zakir M. Hubungan Pengetahuan dan Personal Hygiene dengan Kejadian Keputihan (flour albus) pada Remaja Putri. J Keperawatan [Internet]. 2015;11(1). Available from: https://ejurnal.poltekkes-tjk.ac.id/index.php/JKEP/article/view/378

10. Ariana AP. Aplikasi Metodologi Penelitian Kebidanan Dan Kesehatan Reproduksi. Yogyakarta: Nuha Medika; 2014.

11. Budiman, Riyanto A. Kapita Selekta Kuesioner: Pengetahuan dan Sikap dalam Penelitian Kesehatan. Jakarta: Salemba Medika; 2013.

12. Andira D. Seluk Beluk Kesehatan Reproduksi. Yogyakarta: A+plus Book; 2010.

13. Tulus CWK, Kundre RM, Bataha olanda B. Hubungan Pengetahuan dan Perilaku dengan terjadinya keputihan pada Remaja Putri kelas XI di SMA Kristen I Tomohon. J Keperawatan. 2014;2(2).

14. Irmayanti. Hubungan Pengetahuan dan Sikap Mengenai personal Hygiene dengan Kejadian Keputihan pada Remaja puteri kelas XI SMAN I Anggaberi. J IIm Kesehat Diagn [Internet]. 2018;12(3):301-5. Available from: http://ejournal.stikesnh.ac.id/index.php/jikd/article/view/325

15. Ilmiawati $\mathrm{H}$, Kuntoro K. Pengetahuan Personal Hygiene Remaja Putri pada Kasus Keputihan. J Biom Dan Kependud [Internet]. 2017 Sep 7 [cited 2019 Dec 29];5(1):43. Available from: https://e-journal.unair.ac.id/JBK/article/view/5794 